\title{
A Comparative Study of Conventional Surgical Turbinoplasty Versus Microdebrider Assisted Turbinoplasty Versus Radiofrequency Assisted Turbinoplasty in Cases of Inferior Turbinate Hypertrophy
}

\author{
SAYED M.S. KADAH, M.D.; SAYED M. MEKHIEMAR, M.D.; FATMA M. ABD EL-GABER, M.D. and \\ MAI ALI F. IBRAHIM, M.Sc. \\ The Department of Otorhinolaryngology, Al-Zahraa University Hospital, Cairo, Egypt
}

\begin{abstract}
Background: Nasal obstruction is the most common complaint among patients presenting to otolaryngologists which disturbs the quality of life of the patient. The anterior end of inferior turbinate is the narrowest part of nasal airway, its enlargement cause significant nasal obstruction [1]
\end{abstract}

Patients and Methods: During the period from December 2015 to October 2017, the mean age was ranging from 17 years to 46 years; fifteen patients were females $(50 \%)$ while fifteen patients were females $(50 \%)$ were attending Otorhinolaryngology Department, Al-Zahraa University Hospital, with nasal obstruction and diagnosed as hypertrophied inferior turbinate refractory to medical treatment. The 30 patients selected for this study were randomly assigned to undergo conventional surgical turbinoplasty $(\mathrm{n}=10)$, microdebrider assisted turbinoplasty (MD) $(\mathrm{n}=10)$, and Radiofrequency turbinoplasty $(\mathrm{RF})(\mathrm{n}=10)$.

Results: Microdebrider assisted turbinoplasty is the technique of highest efficacy and leastcomplication. Radiofrequency turbinoplasty is alternative method for the treatment of turbinate hypertrophy. It is the simplest technique and its efficacy is high in long-term olfactory and functional Outcomes. Conventional surgical turbinoplasty is effective as microdebrider but the complication namely crustation and bleeding in this method is higher and time consuming than the other 2 methods.

Conclusion: Both radiofrequency and microdebrider assisted turbinoplasty are efficient methods for relieving nasal obstruction related to inferior turbinate hypertrophy.

Key Words: Nasal obstruction - Turbinate hypertrophy Turbinoplasty - Surgical - Radiofrequency Microdebrider.

\section{Introduction}

CHRONIC nasal obstruction is one of the most common human problems and a very frequent

Correspondence to: Dr. Sayed M.S. Kadah, The Department of Otorhinolaryngology, Faculty of Medicine,

Al-Azhar University symptom in the otorhinolaryngology. Inferior turbinate hypertrophy, which is one of the most common causes of nasal obstruction, may be observed in allergic rhinitis, vasomotor rhinitis, chronic hypertrophic rhinitis or, sometimes, compensatory response to an evident septal deformity [2]

Medical treatment options such as antihistamines, topical decongestants and corticosteroids are commonly prescribed to reduce the size of the turbinate with the aim of restoring nasal function. However, some cases show only slight improvement while some are even refractory to these medical treatments and the patients complain about persistent symptoms. In these cases, surgical reduction of the inferior turbinate can be attempted [3].

Various techniques have been used to reduce the volume of the mucosal and bony parts of the inferior turbinate. Conventional surgical options are total or partial turbinectomy, turbinoplasty, electrocautery and cryosurgery. Although these methods may provide better results than medical treatment alone, adverse effects such as bleeding, crust formation, post operative pain, synechia or atrophy of the inferior turbinate are common [3].

The aim of this study is to assess the efficacy and compare post-operative outcomes of using conventional surgical turbinoplasty, microdebrider assisted turbinatoplasty and radiofrequency assisted turbinatoplasty in the treatment of the hypertrophied inferior nasal turbinate.

\section{Patients and Methods}

A prospective study was performed on $30 \mathrm{pa}-$ tients ranging in age from 17 to 46 years, attending Otorhinolaryngology Department, Al-Zahraa Uni- 
versity Hospital, who presented nasal obstruction and hypertrophied turbinate mucosa refractory to medical treatment, from December 2015 to October 2017. All of these patients had symptoms and signs of nasal obstruction and stuffiness related to congested turbinate mucosa that did not respond well to medical treatment.

Following routine physical ear-nose-throat examination, focusing on detailed nasal examination, every patient underwent endoscopic nasal evaluation. Patients with prominent mucosal hypertrophy were selected by means of a decongestion test because patients with bony hypertrophy, covered with a thin layer of mucosa, are not good candidates for microdebrider-assisted turbinoplasty.

Nasal cavities were decongested for 5 minutes with cotton pledgets soaked with adrenaline at a concentration of $1 / 100,000$. Patients with evident shrinking of their inferior turbinates were included in this study.

Patients having other causes of nasal obstruction as septal deviation/sinusitis/concha bullosa/nasal polyps or tumors of nose and paranasal sinuses were excluded from the study. Patients with history of any previous nasal surgery or systemic disease or previous radiotherapy were also not part of the study.

Informed consent was obtained from all patients. 10 patients ( 7 females, 3 males) were treated with surgical turbinoplasty (Group I) 10 patients (4 females, 6 males) were treated with microdebrider (MD) (Group II) and 10 patients (4 females, 6 males) were treated with radiofrequency (RF) (Group III). The mean patient age was $25 \pm 5$ years for the surgical group, the mean patient age was $20 \pm 2$ years for the microdebrider group and $24 \pm 8$ years for the radiofrequency group.

\section{Surgical procedures:}

Surgeries were done under general hypotensive controlled anesthesia with the patients positioned in the $15^{\circ}$ head up position. Preoperative nasal decongestion for 10 minutes was done using cottonoids soaked in 1: 10000 epinephrine. The rigid $4 \mathrm{~mm}$ endoscopes of different angles $\left(0^{\circ}\right.$ and $\left.30^{\circ}\right)$ were used.

Conventional surgical turbinplasty was performed under general anesthesia. Nasal cavities were packed with $2 \%$ xylocaine with adrenaline (1: 100,000); a 3-4mm mucosal incision was done on the head of the inferior turbinate. The submucosal tissue was dissected from the medial surface and inferior edge of the bone via the mucosal incision assisted by the use of an elevator. The excess cavernous tissue was resected using Hartmann forceps. After surgery, nasal packing with Merocel was continued for 2 or 3 days depending on bleeding which ranged from mild to moderate bleeding.

Microdebrider can be introduced to irrigate and debride the turbinate. It consists of a corded handpiece with a $2.9 \mathrm{~mm}$ turbinate blade attached. Suction and irrigation tubing connects to the base of the handpiece. The shaver blade resects tissue working in an oscillating fashion and is activated via foot pedal. The submucosal tissue was debrided at 3000-rpm oscillating mode in a ventrocaudal manner. Debridement was performed with the blade positioned laterally from the submucosal plane. At times when the bony turbinate was hard to debride, the turbinate bone was transected at its superior surface with long stevens tenotomy scissors and removed. Examination with a 0 endoscope was done to achieve hemostasis under direct vision with suction electrocautery when necessary. The reduction in size of the inferior turbinate was easily recognized immediately after the procedure. The surgical technologist should be prepared to ream the device with a small wire brush should an occlusion occur within the shaft.

Radiofrequency turbinoplasty: No vasoconstrictive agent was used topically or by injection to avoid turbinate shrinkage, which was thought to increase the risk of potential mucosal injury and postoperative complications. The wand was damped with $9 \%$ normal saline to permit the plasma field to form during insertion.

The needle of the probe was inserted submucosally at the anterior head of inferior turbinate and extended to the posterior portion of the inferior turbinate (three entries per turbinate, one at the medial surface of inferior turbinate, one at the turbinate surface facing the inferior meatus and one parallel to the nasal floor). Then, the inferior turbinate was ablated with an output power level of voltage range 168-182 voltage root-mean-squares (Vrms) from posterior to anterior direction. The wand was kept in position for 15 seconds unless the whitening of the overlying mucosa of the applied region was noted. A count of 10 seconds is performed to control the amount of tissue ablated in one area. The withdrawal was performed at coagulation mode. Great care was taken not to injure the mucosa of inferior turbinates. The radiofrequency wand is activated via a foot pedal controlled by the surgeon. Nasal packing with Merocel was used after surgery. Antibiotic therapy 
with amoxicillin and analgesia with acetaminophen were given for 5 days postoperatively. The healing process secondarily induces fibrosis with wound contraction, leading to tissue volume reduction.

\section{Outcome parameters:}

Subjective symptoms, such as nasal obstruction, sneezing, hyposmia and headache, were evaluated on the 7 th day, and in 3 rd months after the procedure using a four-point scale [3] (Tables 1-3).

Table (1): Four-point scale of nasal obstruction.

0 No nasal obstruction.

1 Mild obstruction (causing no disturbance in patient's daily life)

2 Moderate obstruction (forcing the patient to breath through the mouth)

3 Severe obstruction (causing sleep disturbances and decrease in voice quality)

Table (2): Four-point scale of headache.

0 No headache

1 Mild headache (not requiring use of any analgesics)

2 Moderate headache (requiring non-narcotic analgesics for relief from headache)

3 Severe headache (requiring narcotic analgesics for relief from Headache)

Table (3): Four-point scale of hyposmia.

\begin{tabular}{ll}
0 & No hyposmia \\
1 & Mild hyposmia \\
2 & Moderate hyposmia \\
3 & Severe hyposmia \\
\hline
\end{tabular}

The patients' satisfaction with the procedure was evaluated according to a four-point scale preoperatively and on the ${ }^{7^{t h}}$ day, and in the 3 rd months after the procedure [3] (Table 4).

Table (4): Four-point scale of patient's satisfaction.

\begin{tabular}{ll}
\hline 0 & I am not satisfied \\
1 & I am a little bit satisfied \\
2 & I am moderately satisfied \\
3 & I am totally satisfied \\
\hline
\end{tabular}

\section{Statistical analysis:}

Data were analyzed using Statistical Program for Social Science (SPSS) version 20.0. Quantitative data were expressed as mean \pm standard deviation (SD). Qualitative data were expressed as frequency and percentage.

\section{The following tests were done:}

Chi-square $\left(\mathrm{X}^{2}\right)$ test of significance was used in order to compare proportions between two qualitative parameters. A one-way analysis of variance (ANOVA) when comparing between more than two means. The confidence interval was set to $95 \%$ and the margin of error accepted was set to $5 \%$. So, the $p$-value was considered significant as the following:

\section{Probability ( $p$-value):}

- $p$-value $<0.05$ was considered significant.

- $p$-value $<0.001$ was considered as highly significant.

- $p$-value $>0.05$ was considered insignificant.

\section{Improvements subjective symptom:}

Nasal obstruction improved significantly in the first week of the operation in the MD group and surgical group and increased in the 3 rd month of the operation. Nasal obstruction was less evident in the RF group in the first week of the operation then improved in the $3 \mathrm{rd}$ month of the operation.

Severity of sneezing, snoring, headache and hyposmia grades improved significantly in the first week of the operation both in the microdebrider and surgical groups then radiofrequency group and increased in the $3 \mathrm{rd}$ month of the operation.

Intergroup comparisons did not reveal any significant differences between the three methods in the first week and the third months postoperatively $(p<0.05)$. The results are summarized in Figs. (1-5).

In this study, a comparative study was performed after seven days for postoperative complication as bleeding, pain, synechia and crustations.

The study show no significant difference in postoperative complications between the three groups postoperatively (Figs. 6,7).

\section{Patient satisfaction:}

Patient satisfaction levels improved significantly in the first week of the operation in there are no statistically significant improvement in patient between groups. After 7 days of operation Satisfaction levels improved significantly in the MD group and surgical group and increased in the 3 rd month of the operation, While the satisfaction levels are less evident in the RF group in the first week of the operation then improved in the $3 \mathrm{rd}$ month of the operation (Fig. 8). 


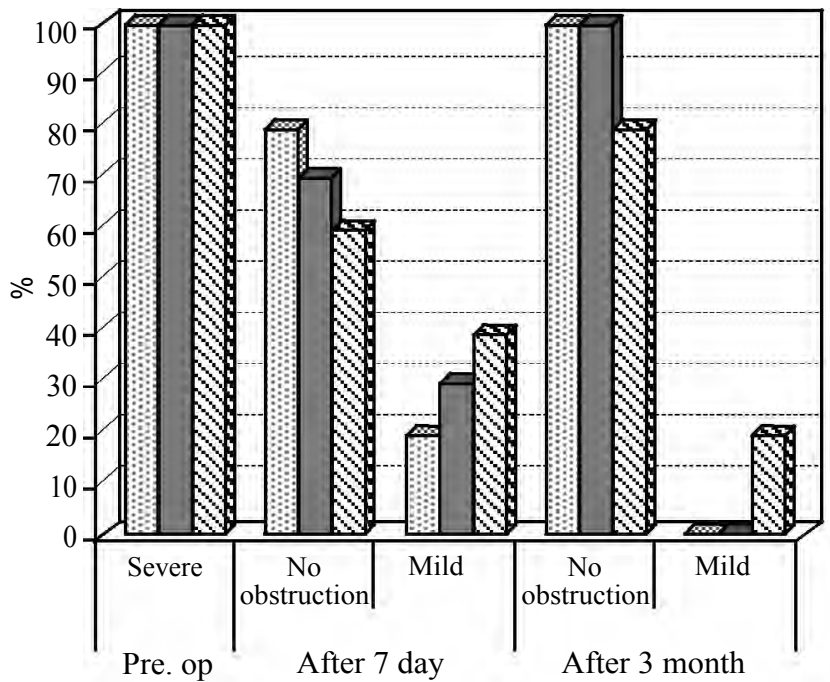

$$
\begin{aligned}
& \text { 图 Group I: Surgical } \\
& \square \text { Group II: Microdebrider } \\
& \text { Q Group III: Radiofrequency }
\end{aligned}
$$

Fig. (1): Bar chart between groups according to nasal obstruction.

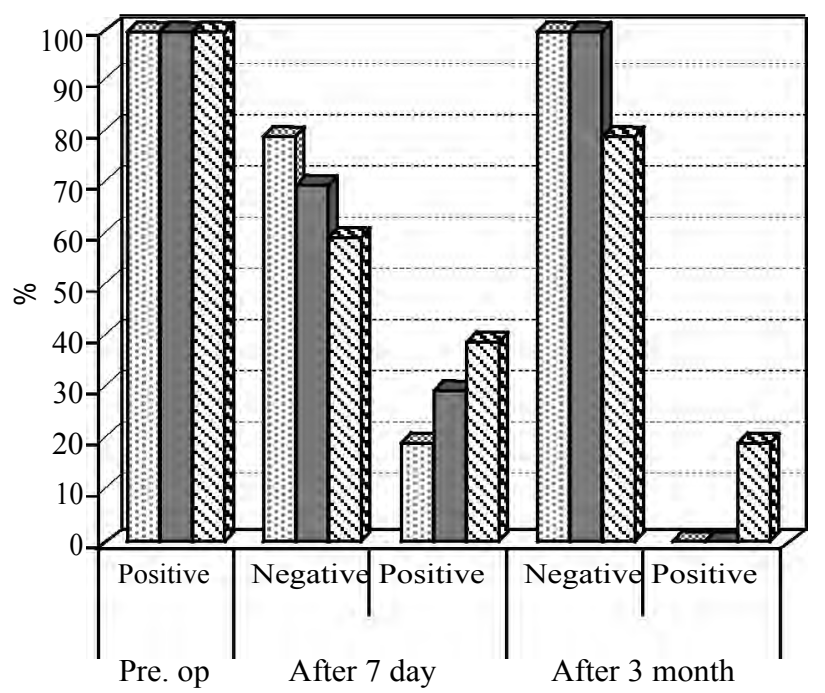

$$
\begin{aligned}
& \text { i] Group I: Surgical } \\
& \square \text { Group II: Microdebrider } \\
& \text { \ Group III: Radiofrequency }
\end{aligned}
$$

Fig. (3): Bar chart between groups according to snoring.

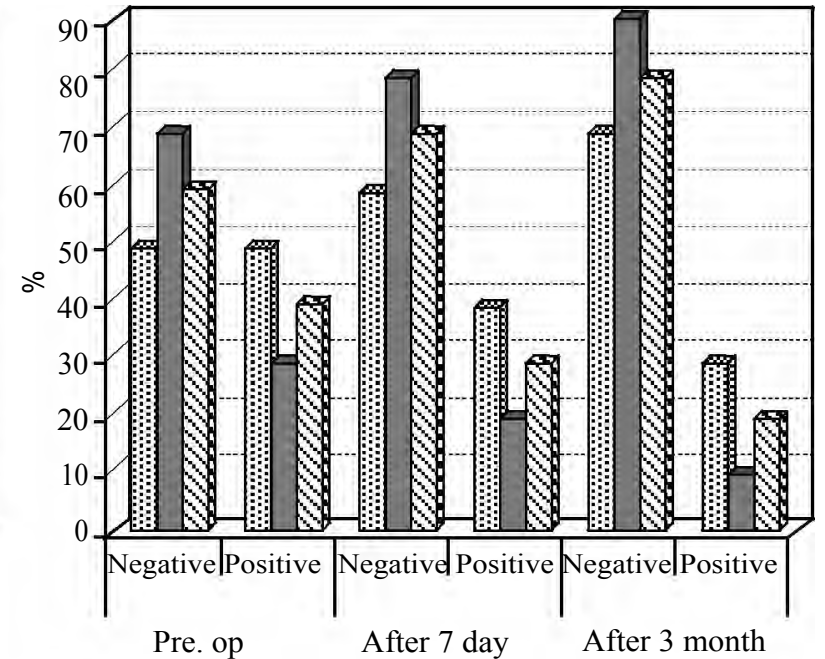

$$
\begin{aligned}
& \text { Group I: Surgical } \\
& \square \text { Group II: Microdebrider } \\
& \text { ه Group III: Radiofrequency }
\end{aligned}
$$

Fig. (2): Bar chart between groups according to sneezing.

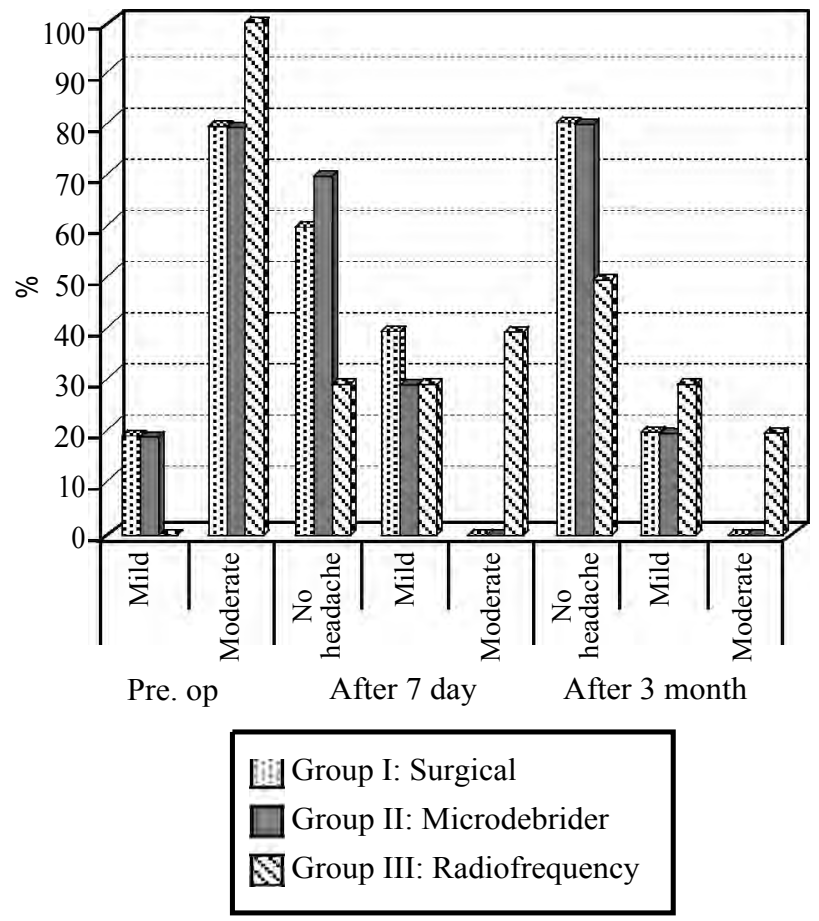

Fig. (4): Bar chart between groups according to headache. 


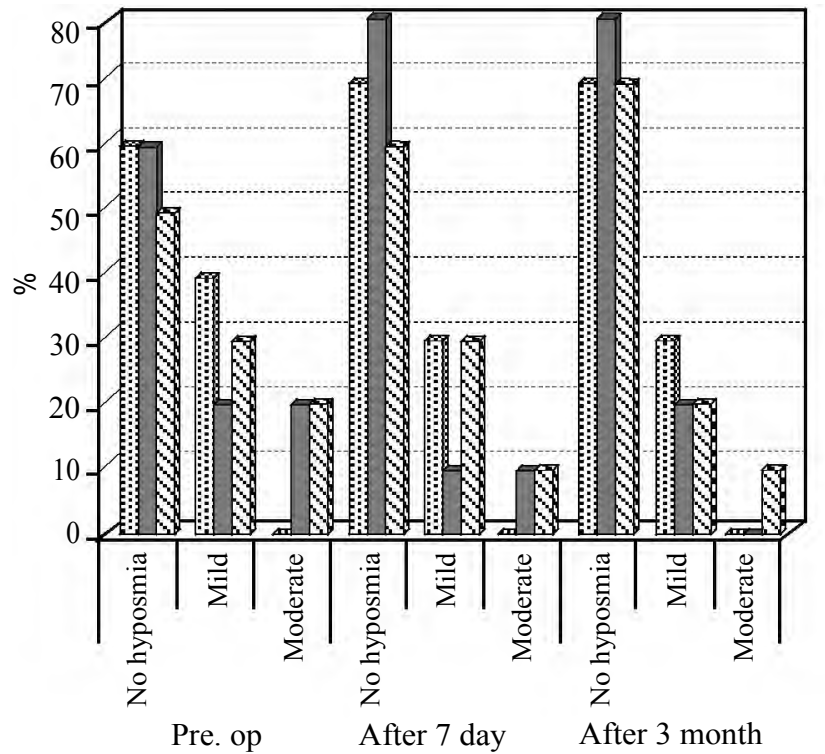

$$
\begin{aligned}
& \text { Group I: Surgical } \\
& \square \text { Group II: Microdebrider } \\
& \text { Group III: Radiofrequency }
\end{aligned}
$$

Fig. (5): Bar chart between groups according to hyposmia.

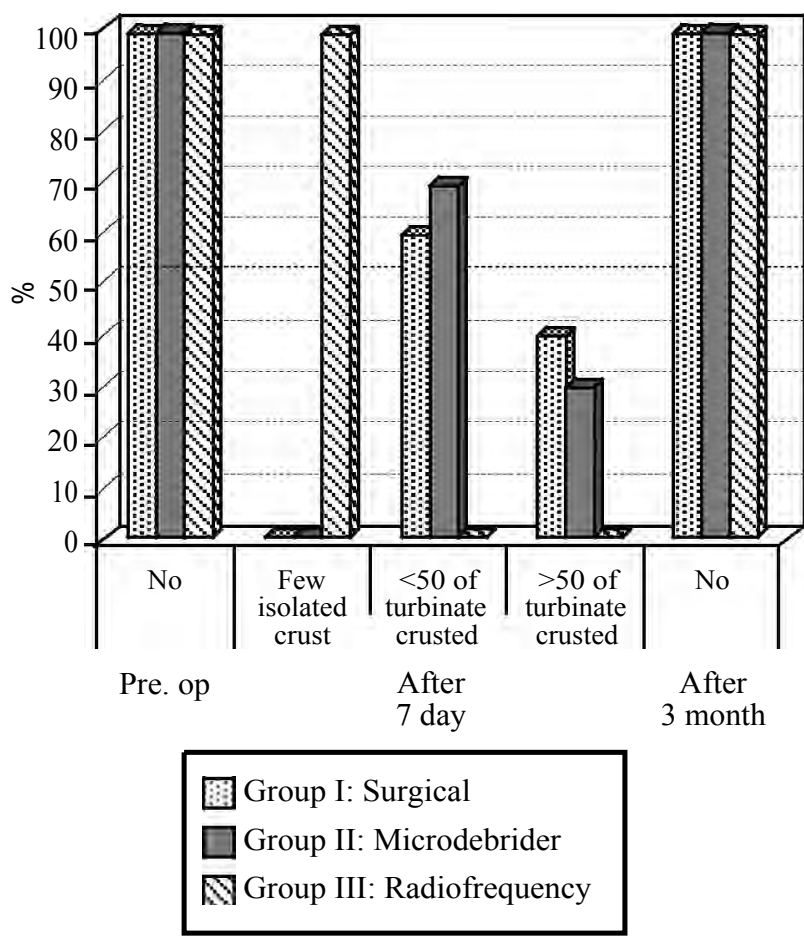

Fig. (7): Bar chart between groups according to crustation.
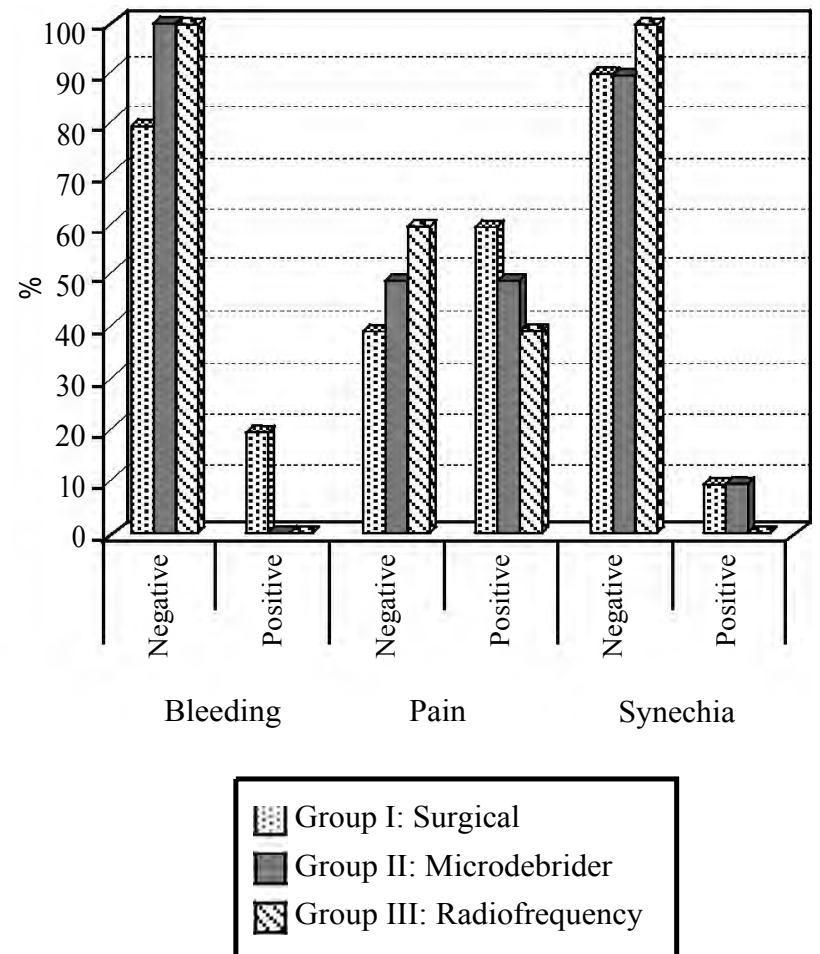

Fig. (6): Bar chart between groups according to post-operative complications.

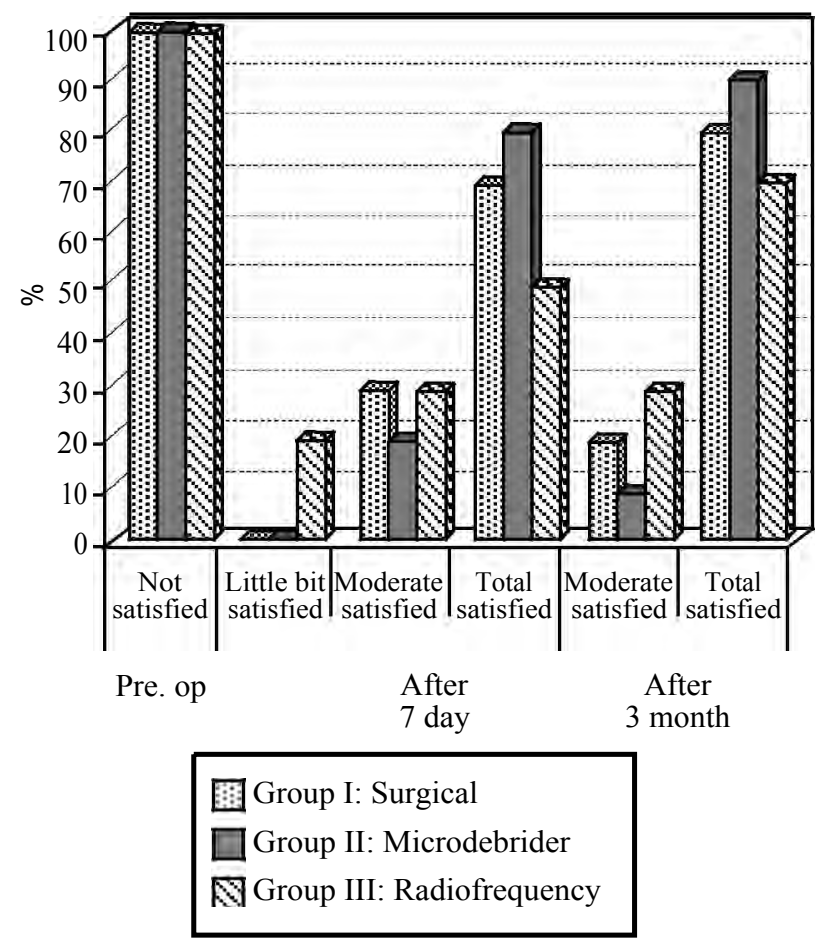

Fig. (8): Bar chart between groups according to satisfaction after operation. 


\section{Discussion}

Most of surgical procedures are destructive, to varying extents, to the respiratory epithelium on the turbinate surface. The main goal of turbinate surgery is to relieve the patient's symptoms of chronic nasal congestion, while preserving mucosal surfaces with reduction of the submucosal and bony tissue [4]

Hoi et al., reviewed all these procedures and concluded that although many of the methods decrease the size of the turbinates, they also damage the mucosal functions of the turbinates thus creating a secondary cause of nasal obstruction [5].

Radiofrequency uses thermal energy to create fibrosis, which causes a decrease in mass of the targeted tissue. Although it is a safe procedure, the desired effects are sometimes seen after a period lasting from days to weeks, because the fibrosis takes some time to shrink the tissue [3]

Microdebrider allows us to effectively remove the bone and soft tissue because its rotation motor can be connected to different types of dissectors and drills. In addition, this tool enables us to obtain excellent surgical visualization because its attached aspirator absorbs the resected material along with any blood, keeping the site free of debris [3]

Lee et al., treated 60 patients with inferior turbinate hypertrophy, 30 of whom were treated with radiofrequency and the remaining 30 with microdebrider. They evaluated post-operative changes in the degree of nasal obstruction in the 3 rd, 6 th and 12 th months after the procedure. They reported that; In group MD, nasal obstruction, rhinorrhea, sneezing and itching were significantly improved during follow-up period (up to 6 months) postoperatively compared to their preoperative levels $(p<0.05)$ and group RF was similar to group $\mathrm{MD}$, but there were three cases of recurrence at 6 th months of postoperative period in group RF with $(p<0.08)$ statistically not quit significant. Also no difference was found in the operation time and post-operative crusting between the two groups [6].

Liu and Tan reported that; RF achieved effects similar to those of MD at 6 months postoperatively $(p>0.05)$, but not at 1,2 , and 3 years postoperatively $(p<0.05)$.

This result could be explained by the fact that thermal injury and fibrosis or shrinkage of the submucosal turbinate tissue, especially the anterior head of the inferior turbinate, could be insufficient in patients with prolonged hypertrophy, leading to unsatisfactory volume reduction at 1,2 , and 3 years postoperatively in RF [4].

Badran et al., reported that; after 3 months, 26 patients $(86.6 \%)$ in the microdebrider group versus 27 patients (90\%) in the surgical group reported marked improvement of nasal obstruction, 2 patients $(6.7 \%)$ in both groups reported mild improvement, 2 patients $(6.7 \%)$ versus 1 patient $(3.3 \%)$ reported no change and no patient reported worsening of nasal obstruction, the difference was not statistically significant $(p>0.05)$ [7].

Sapci et al., reported that RF applied to the turbinates, decrease in symptom severity and frequency of nasal obstruction were reported in $81 \%$ to $100 \%$ of cases. Additionally, they used magnetic resonance imaging (MRI) to evaluate inferior turbinate volumes, and had shown objectively an $8.7 \%$ reduction in inferior turbinate volume [8].

Kizilkaya et al., applied RF and microdebriderassisted turbinoplasty to 30 patients, choosing one method for one nasal passage and the other for the opposite side. They compared improvements in nasal obstruction, nasal mucociliary function. In the MD group, nasal obstruction, rhinorrhea, sneezing, and snoring significantly improved 6 months to 3 years postoperatively compared to their preoperative levels $(p<0.05)$. Although all the symptom scores of the RF group significantly improved 6 months to 1 year postoperatively compared to their preoperative levels $(p<0.05)$, no further improvement occurred at 2 and 3 years postoperatively $(p>0.05)[9]$.

Cingi et al., reported that severity of nasal discharge, headache and hyposmia grades improved significantly in the first week of the operation both in the MD and RF group and persisted in the $1 \mathrm{st}$ and $3 \mathrm{rd}$ month of the operation. Intergroup comparisons did not reveal any significant differences between the two methods postoperatively $(p<0.05)$. Since MD can effectively widen the nasal airway; They concluded that microdebrider-assisted partial turbinoplasty is more effective and satisfactory in relieving nasal obstruction [3].

Garzaro et al., demonstrated that surgical enlargement of the spaces medial to the lower middle turbinate could provide olfaction improvement and odor thresholds are affected by inter individual differences in volumes of the inferior meatus remote from the olfactory cleft. They reported that Surgery improved olfactory function in both smokers and 
non smokers, although the analysis of variance before, 2 months, and 2 years after treatment showed that only the olfactory threshold was significantly related to smoking: The mean improvement in olfactory threshold was more consistent among non smoking patients $(p<0.05)$. There were no correlations between allergy and improvement in olfactory function $(p=0.2)[10]$

Badran et al., reported that no patient had any postoperative bleeding in the microdebrider group after pack removal. Two patients of the surgical group $(6.7 \%)$ showed secondary hemorrhage 1 week after surgery which was controlled by antibiotics and nasal packings. We did not encounter any crusting, foul odor, synechia or atrophic change during the next 3 months in either group. The difference was not statistically significant ( $p=0.472$ ) [7]

Kumar reported that; the most common side effects of RF are pain during the procedure. Hytönen et al., evaluated 35 studies and found that the most common complaint was preoperative or postoperative pain $[\mathbf{2}, \mathbf{1 2}]$.

Corso et al. reported that three out of 14 patients had severe pain during the procedure and that the intervention was stopped in two patients. They mentioned that there was no post operative pain,or the patients had minimal pain controlled with analgesics [11]

Cingi et al., compared Microdebrider-assisted versus radiofrequency assisted inferior turbinoplasty. There were minimal crusatations and synechie among the microdebrider group in the early preoperative period compared to obvious postoperative edema and crustations among the other group [3].

Lee and Lee reported a comparative study was done on radiofrequency assisted and microdebrider assisted turbinoplasty. No difference was found, in the operation time and post-operative crusting, between the two groups [6].

Cingi et al., reported that patient satisfaction with the procedure levels improved significantly better in the MD group in the first week, the first month and the third month and postoperatively compared with the radiofrequency group $(p<0.05)$. Long-term satisfaction rates in the RF group were not as high as expected. These results can probably be explained by the fact that radiofrequency assisted turbinoplasty may cause oedema in the tissue, which starts a few days after the procedure. Pro- longed or latent oedema may also be the factor cause the long term decrease in patient satisfaction of the RF group [3]

Kumar reported that; There were 3 cases of recurrence in group RF however no recurrence was noted in group MD at 6 months postoperatively. Statistical comparison was made by using $t$-test and considered not quite significant with $p$-value of 0.0831 [2]

\section{Conclusions:}

Both radiofrequency and microdebrider turbinoplasty are efficient methods for relieving nasal obstruction related to inferior turbinate hypertrophy. Both procedures have similar complication rates. However, microdebrider should be preferred because subjective and objective nasal obstruction improvement in the microdebrider group has been proven to be better than that in the radiofrequency group in the short- and the long-term.

\section{References}

1- WALSH W.E., KERN R.C., FRIEDMAN M. and VIDYASAGAR R.: Sinonasal anatomy, function, evaluation, surgical management of septal deformity, turbinate hypertrophy, nasal valve collapse, and choanal atresia. Head and Neck Surgery-Otolaryngology, 4 th edn., pp. 307-313 2006.

2- KUMAR K.: A Comparative Study of Radiofrequency Assisted Versus Microdebrider Assisted Turbinoplasty in Cases of Inferior Turbinate Hypertrophy; Indian J. Otolaryngol Head Neck Surgery, 66 (1): 35-39, 2014.

3- CINGI C., URE B. and CAKLI E.H.: Microdebrider-assisted versus radiofrequency assisted inferior turbinoplasty: A prospective study with objective and subjective outcome measures. ACTA Otorhinolaryngologica Italica, 30: 138143,2010 .

4- LIU C.M. and TAN C.D.: Microdebrider-assisted versus radiofrequency-assisted inferior turbinoplasty. Laryngoscope, 119: 414-418, 2009.

5- HOI K.S. and HUIZING H.: Function of turbinate; a review and critical evaluation of the different techniques; Rhinology, 38: 157-166, 2000.

6- LEE J.Y. and LEE J.D.: Comparative study on the long-term effectiveness between coblation and microdebrider assisted partial turbinoplasty. Laryngoscope, 116: 729-734, 2006.

7- BADRAN H., HESHAM A. and HUSSEIN A.: Intraturbinal versus extra turbinal microdebrider-assisted inferior turbinoplasty: Preliminary results, Egyptian Journal of Ear, Nose, Throat and Allied Sciences, 15: 1-5, 2014

8- SAPCI T., GUVENÇ M.G. and EVCIMIK M.F.: Radiofrequency treatment for inferior turbinate hypertrophy Laryngoscope, 117: 56-60, 2007.

9- KIZILKAYA Z., CEYLAN K. and EMIR H.: Comparison of radiofrequency tissue volume reduction and submucosal resection with microdebrider in inferior turbinate hypertrophy. Otolaryngol. Head Neck Surg., 138: 176-81, 2008. 
10- GARZARO M.: Radiofrequency Inferior Turbinate Reduction: Long-Term Olfactory and Functional Outcomes Otolaryngology Head and Neck Surgery, 146 (1): 146150, 2011.

11- CORSO E.D., BASTANZA G. and DONFRANCESCO V.D.: Radiofrequency volumetric inferior turbinate reduction:
Long-term clinical results; Acta. Otorhinolaryngologicaitalica, 36: 199-205, 2016.

12- HYTONEN M.L., BACK L.J., MALMIVAARA A.V. and ROINE R.P.: Radiofrequency thermal ablation for patient with nasal symptoms; a systematic review of effectiveness and complications. Eur. Arch. Otorhinolaryngol., 266: 1257$1266,2009$.

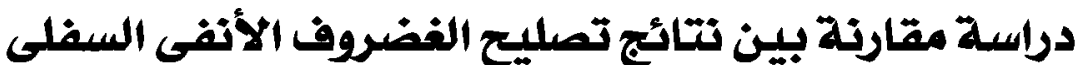

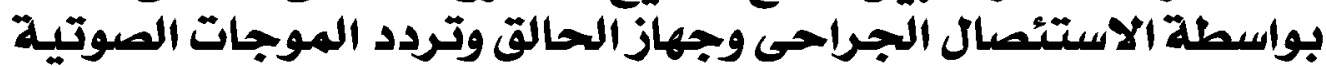 لعلاج تضخم فضراريف الأنف السفلية الهردية}

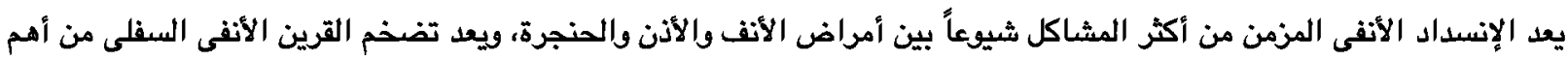

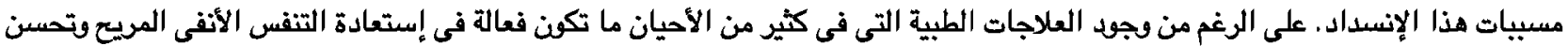

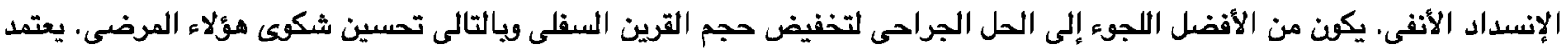

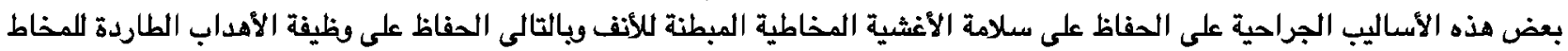
الأنفى والبعض الأخر لا يعتمد على ذلك.

تهدف هذه الدراسة إلى دراسة مقارنة بين نتائج تجميل الغضروف الأنفى السفلى بإستخدام الحالق وتردد الموجات الصوتية والاستئصال الجراحى لعلاج تضخم غضاريف الأنف السفلية.

بعد تنفيذ تلك الدراسة، اتضِح أن كلاً منهما يعد وسيلة فعالة للتخفيف من الإنسداد الأنفى المتعلق بتضخم القرين السفلى، فأن كلاً الإجرانين لديهما معدلات مضاعفات مهاثلة.

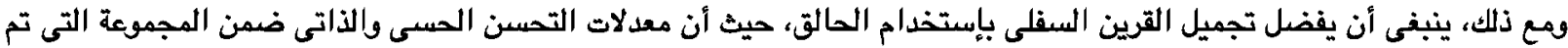

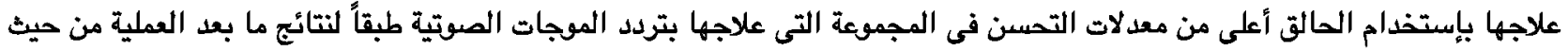
التقدم وكم الإفرازات وتصسن الانسيداد الانفى. 